\title{
Onomasiologia e semasiologia revisitadas pela ecolinguística
}

\author{
Onomasiology and semasiology revisited by \\ ecolinguistics
}

\section{Hildo Honório do Couto Universidade de Brasília}

\section{Resumo}

O objetivo deste artigo é retomar os conceitos de onomasiologia e semasiologia. Após uma conceituação e histórico deles, mostro que, pelo menos na Alemanha, eles continuam sendo utilizados e que, devem ser resgatados, uma vez que são muito úteis nos estudos semânticos, sobretudo no que tange à referência. Na relação palavracoisa, o primeiro deles vai do conceito / coisa para a palavra e o segundo da palavra para o conceito / coisa. Termino mostrando algumas aplicaçōes dos dois na ecologia da interação comunicativa, ponto de partida da jovem disciplina Ecolinguística, no estudo das preposiçōes espaciais e na sintaxe.

\section{Palavras-chave}

Onomasiologia, Semasiologia, Referência, Preposiçōes espaciais, Morfossintaxe.

\section{Abstract}

The objective of this article is to revisit the concepts of onomasiology and semasiology. After defining them and outlining their history, I show that they are still used, mainly in Germany, and are useful in the semantic studies, especially in the case of reference. Onomasiology goes from the thing to the word, whereas 
the latter goes in the opposite direction. They are also applied in the ecology of communicative interaction, the kernel of the young discipline Ecolinguistics, as well as in syntax and the semantic study of spatial prepositions.

\section{Keywords}

Onomasioloy, Semasiology, Reference, Spatial prepositions, Morphosyntax. 


\section{Introdução}

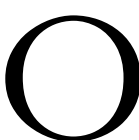

estudo de Kurt Baldinger intitulado "Semasiologia e onomasiologia", publicado originalmente na Revue de Linguistique Romane (XXVIII, 1964), foi reproduzido em português como Baldinger (1966), talvez a primeira divulgação detalhada do assunto no Brasil. Trata-se de um minucioso apanhado geral dos dois conceitos, com muitos exemplos e gráficos que facilitam o entendimento do que eles significam. O que pretendo fazer neste ensaio é sugerir que, a despeito de andar um tanto desprestigiada nos dias atuais, a dicotomia pode e deve ser retomada no contexto dos estudos semânticos. Entendo-os no sentido que têm na distinção semiótica feita entre semântica, sintaxe e pragmática, sendo tudo inserido no âmbito mais geral da jovem disciplina Ecolinguística.

As ideias que levaram à dicotomia "onomasiologia e semasiologia" começaram já no século 19, ou até antes. Ao longo da primeira metade do século 20 , grande parte dos estudiosos da linguagem se pronunciou a favor de ou contra a visão semasiológica e/ou a onomasiológica. Rudolf Meringer, criador da revista Wörter und Sachen (palavras e coisas), é um deles. A finalidade principal da publicação era justamente defender a visão onomasiológica. Um outro é Hugo Schuchardt, talvez até mais radicalmente onomasiologista do que Meringer. Ele propôs que se dissesse Sachen und Wörter (coisas e palavras), uma vez que a coisa precederia a palavra em todo sentido. Embora os dois autores tivessem chegado à onomasiologia independentemente um do outro, houve muita crítica de um ao outro, sobretudo de Meringer a Schuchardt. Meringer achava que tinha levantado a questão primeiro, revelando às vezes até um certo ciúme de Schuchardt.

Alguns dos outros nomes de estudiosos que se dedicaram à questão em tela aparecerão abaixo. Por isso, gostaria apenas de salientar aqui alguns nomes de brasileiros e portugueses que se interessaram pelo assunto. Entre os segundos, podemos alinhar Adolfo Coelho, Manuel de Paiva Boléo e Herculano de Carvalho. No Brasil, sobressai-se Serafim da Silva Neto, que, além de ter discutido a questão 
do ponto de vista teórico, escreveu alguns ensaios onomasiológicos. Em Miazzi (1972, p. 63-67) há um pequeno esboço histórico dos dois conceitos.

No restante deste ensaio temos, na seção 2, uma conceituação e um breve esboço histórico de onomasiologia e semasiologia, partindo dos proponentes dos termos, passando por alguns de seus seguidores até chegar a alguns críticos deles. $\mathrm{Na}$ seção 3, discuto alguns desdobramentos ulteriores dos dois conceitos, incluindo-se usos mais recentes que se têm feito deles e publicaçōes disponíveis na internet. Uma vez que os dois surgiram no contexto da relação entre palavra e coisa, a seção 4 é dedicada a ela, sob o nome de relação língua-mundo. A seção 5 procura inserir esse estudo no contexto maior da Ecolinguística, que é definida como estudo das relações entre língua e meio ambiente, tomando-se a última expressão no sentido de entorno da língua. A Ecolinguística enfatiza sempre a tese de Coseriu (1967) de que a língua é basicamente comunicação, de que ela existe no falar. Por isso, a seção 6 procura mostrar a importância de onomasiologia e semasiologia na ecologia da interação comunicativa. A seção 7 discute a utilidade das duas abordagens no estudo das preposições. Ele deve se iniciar onomasiologicamente, porém, o procedimento deve ser complementado por uma investigação semasiológica. Essa segunda etapa dos estudos, dada sua importância nas pesquisas atuais, pode ser chamada de virada semasiológica. Na seção 8 , tento fazer um estudo onomasiológico de aspectos da morfossintaxe portuguesa, ainda que de modo bastante incipiente. Por fim, temos as observaçóes finais.

\section{Conceituação e histórico de onomasiologia e semasiologia}

Como já foi sugerido acima, os conceitos de onomasiologia e semasiologia têm a ver com a relação palavra-coisa, que, em princípio, pode ser vista de qualquer uma das duas perspectivas. Essa relação será detalhadamente discutida na seção 4. No entanto, gostaria de enfatizar já aqui que a onomasiologia vê a questão da referência, para usar um termo semiótico, partindo da coisa e indo na direção do nome que ela recebe. A semasiologia, no mesmo contexto, faz o percurso inverso, partindo da palavra e indagando a que coisa, ou coisas, ela se refere. O termo "semasiologia" surgiu bem antes do de "onomasiologia", ou seja, em 1825, nas Vorlesungen über lateinische Sprachwissenschaft (Preleções sobre a linguística latina), de Christian Carl Reisig, ministradas na Universidade de Halle e publicadas em 1839. Pouco depois, seguidores seus trilharam o mesmo 
caminho. Um deles é Friedrich Haase, com uma obra com o mesmo nome. Outro é Ferdinand Heerdegen, que publicou três cadernos sob o nome de Untersuchungen zur lateinischen Semasiologie (Investigaçôes sobre a semasiologia latina), em 1875-1881, e Lateinische Semasiologie (Berlim, 1890).

Um termo alternativo que se tem usado na Alemanha para semasiologia, Bedeutungslehre (ciência da significação), já aparecia na época, como se pode ver em Die griechische Bedeutungslehre, eine Aufgabe der klassischen Philologie (A ciência da significação grega, tarefa da filologia clássica), de M. Hecht (Leipzig, 1888). Como se vê, o termo "semasiologia" surgiu inclusive antes do de semântica, que apareceu pela primeira vez no Essai de sémantique de Bréal, de 1897. Naquele tempo, a semasiologia fazia aproximadamente o que hoje se faz sob o rótulo de semântica. Uma única diferença, se é que se trata de diferença, é que a primeira estava mais preocupada com a mudança de sentido das palavras, embora a semântica também colimasse esse fim.

Existem algumas publicações clássicas sobre a semasiologia. Entre elas poderíamos mencionar o Handbuch der Semasiologie (Manual de semasiologia), de Heinz Kronasser (Heidelberg: Winter, 1968), que procurou dar uma explicação psicológica para a mudança da significação das palavras. Uma outra é a de Kurt Baldinger, Die Semasiologie - Versuch eines Überblicks (A semasiologia - tentativa de visão de conjunto), publicada em Berlim, pela Akademie-Verlag, em 1957.

Vejamos a onomasiologia, também chamada de Bezeichnungslehre (ciência da denominação), que surgiu como reação aos neogramáticos (AMMIROVA; OL'CHOVIKOV; ROŽDESTVENSKIJ, 1980 p. 436). O termo em si foi proposto por Adolf Zauner, em sua tese de habilitação Die romanischen Namen der Körperteile (Os nomes românicos das partes do corpo), apresentada à Faculdade de Viena em 1902 e publicada pela primeira vez no mesmo ano. É interessante notar que ele sempre teve a acepção que acaba de lhe ser dada, ao passo que semasiologia sempre se confundiu com sematologia, com semântica e até com semiótica. Essas incertezas talvez sejam algumas das razões para o maior prestígio da onomasiologia nos dias atuais, além do fato de o percurso da coisa à palavra ser muito mais simples e natural do que o contrário.

Como observou Baldinger (1966, p. 9), Karl Vossler confrontou os dois conceitos, mostrando que são complementares, fato que já estava sugerido em Zauner. Este já conceituava onomasiologia como respondendo à pergunta sobre como a língua expressa determinado conceito. Ainda segundo o autor, pode-se ver que onomasiologia e semasiologia se complementam. A primeira parte de fora, 
do conceito (da coisa), e procura pela denominação que ele recebe, ao passo que a segunda parte de dentro, da palavra, de modo que há um paralelismo reverso entre elas.

Alguns autores apresentam uma divisão da história da onomasiologia em três fases. A primeira fase é a da emergência, em que as primeiras análises de dados concretos foram feitas. Associava-se a coisa à palavra, levando-se o princípio onomasiológico ao pé da letra. A segunda corresponde ao período do movimento Wörter und Sachen, que deu lugar ao surgimento da revista homônima em 1909, em Graz (Áustria), cujo mentor era Rudolf Meringer, embora outros nomes tenham participado do grupo, como Hugo Schuchardt, além de W. MeyerLübke, J. J. Mikkola e R. Much.

Num longo texto intitulado "Sobre os objetivos e o nome de nossa revista", Meringer, que se considerava discípulo do criador da Wellentheorie (teoria das ondas), Johannes Schmidt (1843-1901), começa dizendo que suas "publicaçóes sobre estudos de coisas começaram em 1891; os estudos sobre elas muito antes”, sempre polemizando com Schuchardt e tentando mostrar que foi ele (Meringer) que iniciou esse tipo de estudo. Para ele, "pesquisa de coisa e pesquisa de palavra precisam alimentar-se mutuamente". Assevera que "é inteiramente descabido encarar a significação como algo existente por si mesmo”, independente da coisa. Nesse contexto, "a pesquisa da coisa não é simples auxiliar da etimologia; pesquisa linguística sem pesquisa de coisa não é mais aceitável” (MERINGER, 1912).

Essa última asserção já inclui a questão da mudança linguística. $\mathrm{Na}$ verdade, a relação entre palavra e coisa é sempre vista da perspectiva evolutiva. Tanto que, para o autor, "mudança de significação é mudança de coisa". Tudo isso se dá no contexto da interação comunicativa, sendo que "a imitação exerce um papel decisivo nas mudanças linguísticas". Na prática, "não é a linguagem que é imitada própria e diretamente, mas tudo que circunda a pessoa serve de modelo de comportamento".

Para Meringer, "o que não conhecemos não podemos passar a conhecer pelo simples contato com a palavra”, assunto que também Schuchardt salientou de modo até mais enfático. Acrescenta que, "sem ciência da coisa não há ciência da linguagem", tanto que "toda contribuição à história da coisa é uma contribuição à história da linguagem”. Por fim, o autor diz que os citadinos não conhecem uma série de coisas, como nomes de cores, de árvores, de plantas e de animais. Sua capacidade de nomear as coisas que os rodeiam é bem pequena. No próprio jardim há uma série de coisas que não identificam nem nomeiam. 
Hugo Schuchardt foi até mais radical do que Meringer. Tanto que inverteu a ordem dos termos, falando em "Sachen und Wörter" (coisas e palavras). O que é mais, para ele o "e" que une as duas palavras deve ser entendido como um símbolo de multiplicação, e não apenas de adição. Com isso, teríamos uma história da palavra-coisa (Sachwortgeschichte). Ele escreveu pelo menos três textos especificamente sobre o assunto, além de análises de dados concretos. $\mathrm{O}$ mais detalhado deles é Schuchardt (1912), no qual começa dizendo que "em uma comunidade linguística unificada a equação entre coisa e palavra é tida como autoevidente". Ele vai mais longe, afirmando que o princípio se aplica também à frase, ou seja, "assim como um ser ou um evento é descrito pela frase, assim também uma coisa é referida pela palavra". Por isso queremos sempre saber a que coisa determinada palavra se refere, perguntando: "O que significa esta palavra?" Para o autor, "a coisa subsiste por si própria; a palavra só na dependência da coisa, sem a qual é apenas um som vazio". Schuchardt evoca o dito dos escolásticos medievais, segundo o qual "Voces significant res mediantibus conceptibus".

Na tradução de Silva Neto (1957, p. 203), temos: "As coisas andam estreitamente ligadas às palavras que as representam. A etimologia de um objecto pode dar-nos a forma deste no momento de originar-se o nome, mas nada nos diz acerca da evolução ulterior. Ao contrário, o conhecimento da história do objecto é exigência primordial para a etimologia e para a evolução do sentido". Um pouco mais adiante, vemos que "as legendas de uma planta ou de uma garrafa de vinho, se delas se perderem, por si nada nos dirão acerca do lugar onde estavam seguras, ao passo que, mesmo sem o letreiro, a planta e o vinho podem ser cabalmente reconhecidos. Por isso, em relação à palavra, ocupa o objecto o lugar primário e invariável: o vocábulo a ele está ligado e ao redor dele gravita".

É necessário ressaltar que Schuchardt reconhece também o valor da semasiologia, embora não tenha usado o termo. Para ele, "por meio das palavras podem ser reveladas propriedades, idade e disseminação da coisa”. Tanto que, em sua opinião, a pesquisa das coisas e a das palavras não têm andado de mãos dadas como deveriam. Os dicionários deveriam ser Wörtersachenbü̈cher (dicionários palavras-coisas) ou Sachenwörterbücher (dicionários coisas-palavras). Só assim a lexicografia progrediria. Por fim, é bom lembrar que as coisas denominadas pelas palavras não devem ser encaradas isoladamente, mas em grupos, como as da flora, da fauna, de partes do corpo e outras. Com isso, podemos passar à terceira fase da onomasiologia, a que começou a se associar aos campos lexicais, ou melhor, campos semânticos. 
Como salienta Schaff (1974, p. 15-48), em um apanhado filosófico geral da teoria do campo semântico, a ideia recua a Herder (1744-1803) e a Humboldt (1767-1835), tendo tido também influência do conceito de sistema de Saussure (1973, p. 20-22). O nome mais proeminente na área é o de Jost Trier, no clássico Der deutsche Wortschatz im Sinnbezirk des Verstandes (1931). Em Trier (1966), vê-se que o autor defende a ideia de que as palavras e seus significados não existem, nem evoluem, isoladamente. Segundo ele, "o vocabulário de uma língua é como uma casa, de que existem partes de grande estabilidade". Assim, as palavras fünf (cinco) e Vater (pai) são bastante duradouras, mas pares como "gross/klein" (grande/pequeno) e rechts/links (direita/esquerda) podem mudar, embora apenas na forma (o tijolo), porque a função exercida por essa forma continua a mesma.

O mesmo já não acontece no domínio cultural. No século 13, o alemão dispunha das palavras Kunst (arte), List (artifício, habilidade, artesanato) e Wisheit (saber, sabedoria), na área semântica de conhecimento. Tudo isso para distinguir o "conhecimento" dos nobres (Kunst) do dos plebeus (List). Um século depois, List desapareceu e surgiu Wizzen (o saber). Com isso, houve um rearranjo geral nesse campo semântico, de modo que Kunst continuou sendo arte, como em arte de cavalgar, Wizzen se aplica ao saber em geral, com o que Wisheit deixa de cobrir o domínio de Kunst e Wizzen.

Algo parecido poderia ser dito de palavras como ter, possuir e haver. A primeira tomou o lugar da terceira, sendo que a segunda tende a assumir o lugar da primeira (ver também GUIRAUD, 1969, p. 77-80 e ULLMANN, 1970, p. 518-520).

Como sabemos, as ideias de Herder e Humboldt vão no sentido de que a linguagem cria o mundo, com o que se privilegiaria a visão semasiológica, sendo que a escola Wörter und Sachen fazia justamente o contrário, dando prioridade à onomasiologia. Tanto que um dos estudiosos de campos semânticos, Leo Weisgerber, é seguidor confesso e entusiasta de Humboldt. Ele criticou acerbamente a própria semasiologia. De qualquer forma, uma inovação importante dessa orientação é a visão orgânica da língua, que não seria um amontoado de disjecta membra.

Baldinger (1966) é uma boa fonte de informação sobre a dicotomia onomasiologia / semasiologia. Embora ele afirme que "a semasiologia [...] considera a palavra isolada no desenvolvimento de sua significação, enquanto que a onomasiologia encara as designaçóes de um conceito particular, vale dizer, uma multiplicidade de expressões que formam um conjunto" (p. 8), seu artigo 
contém uma seção intitulada "O campo semasiológico". Aí ele faz uma detalhada análise de trebalh e trebalhar em provençal antigo, apresentando mais de 14 acepções que a palavra pode ter.

$\mathrm{Na}$ dinâmica evolutiva e geográfica da língua, a palavra passa a ter conotaçóes diferentes, com o que nunca temos sinônimos perfeitos. Para o autor, "o emprego da palavra numa situação precisa condiciona uma nova significação, o que exige, no dicionário, uma definição nova". Isso porque a palavra "adquire [...] um matiz que deriva da situação" (p. 15). Salienta o autor, outrossim, que pode haver mudança de centro significativo. Assim, no "estudo da modificação da estrutura semasiológica - no caso de travail, [houve] a passagem do campo que tem por centro 'peine, tourment' para o campo cujo centro é 'travail”' (p. 19).

Para visualizar tudo que vem sendo dito das relaçôes onomasiológicas e semasiológicas, vejamos as representaçôes da seguinte figura, que parte do signo de Peirce, como fez Baldinger (1966).

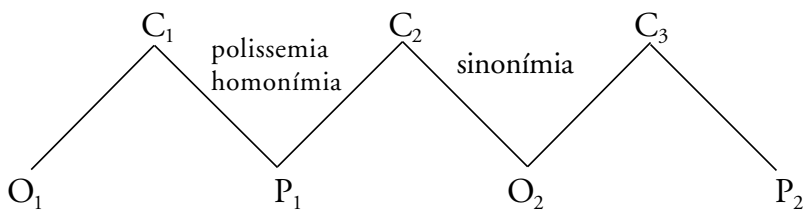

Da perspectiva onomasiológica, podemos partir da coisa ou objeto $\left(\mathrm{O}_{2}\right)$, que está associada aos conceitos $\left.\mathrm{C}_{2}, \mathrm{C}_{3}\right)$. $\mathrm{O}$ primeiro está ligado à palavra $\left(\mathrm{P}_{1}\right)$; o segundo, à palavra $\mathrm{P}_{2}$. Do ponto de vista semasiológico, partimos da palavra $\left(\mathrm{P}_{1}\right)$, que se associa a mais de um conceito, $\mathrm{C}_{1}$, e $\mathrm{C}_{2}$, sendo que $\mathrm{C}_{1}$ está ligado a um objeto $\left(\mathrm{O}_{1}\right)$ e $\mathrm{C}_{2}$ a $\mathrm{O}_{2}$. Partindo de $\mathrm{P}_{1}$, podemos ter polissemia ou homonímia (uma palavra associada a mais de um conceito), conforme o caso; partindo de $\mathrm{O}_{2}$, temos sinonímia (dois conceitos associados ao mesmo objeto). A representação é esquemática. Ela mostra apenas uma possibilidade, entre inúmeras outras.

\section{Outros desdobramentos de onomasiologia e semasiologia}

$\mathrm{Na}$ seção anterior, foi dada muito mais atenção à onomasiologia do que à semasiologia, o que daria a falsa impressão de que ela teria mais importância. Isso não é verdade. Onomasiologia e semasiologia são duas faces da mesma moeda, portanto, nenhuma delas é mais importante do que a outra, mesmo porque 
a moeda não pode ter uma face maior do que a outra. Tampouco pode ela ter só uma face. De qualquer forma, quando observamos as coisas geneticamente, a onomasiologia nunca deixa de ter uma certa primazia, quando não pelo fato de ser o ponto de partida, como fez seu criador e seus usuários ulteriores, tais como Meringer e Schuchardt. Pode ser que a semasiologia venha sendo menos usada devido à confusão que se tem feito entre ela, semântica, sematologia e até semiótica.

O fato é que hoje em dia ainda se fala em onomasiologia, sobretudo nos estudos de geografia linguística, de dialetologia, de geolinguística e de atlas linguísticos. Ela tem sido posta em prática também por alguns pesquisadores do léxico, além dos que o faziam na linha da escola Wörter und Sachen. Atualmente, existem sites na internet dedicados sobretudo à onomasiologia. Um deles é Onomasiology Online, sediado na Universidade de Eichstätt, de Ingolstadt, Alemanha. ${ }^{1}$

Essa publicação já passou do décimo número. No total são mais de 20 artigos, que tratam tanto de questões teóricas quanto de assuntos práticos. A maior parte dos estudos é de cunho onomasiológico, embora haja alguns que incluem o aspecto semasiológico. Há outros sites, em outras universidades, como a de Trier, também na Alemanha.

De qualquer forma, como contraponto da onomasiologia, a semasiologia sempre vem mencionada. Tanto que na Wikipedia em alemão, há um pequeno texto sobre semasiologia, ao lado de outro bem mais detalhado sobre onomasiologia. Em cada um deles se faz referência ao outro. Esses textos devem ter sido escritos pelo organizador de Onomasiology Online, o onomasiologista Joachim Grzega. O fato é que a semasiologia é a ciência das significações das palavras, uma vez que semioticamente ela é parte da semântica. Ela é um método lexicológico e lexicográfico. De acordo com ela, se parte de uma palavra e se dão suas significações. Os dicionários monolíngues normais que utilizamos são todos de cunho semasiológico.

Acima vimos, com Baldinger, uma discussão sobre o campo semasiológico, que seria mais um campo lexical. No caso da onomasiologia, trata-se de campo semântico, uma vez que o ponto central é o conceito, a coisa designada. Poderíamos pensar nos campos semânticos da flora, da fauna e assim por diante.

Há muitas outras aplicações dos dois conceitos em tela. Uma delas é à aquisição de L1 pela criança. A primeira coisa que Aninha identificou foi a água, dando-lhe o nome $a b a$, num percurso claramente onomasiológico. Só que água para ela compreendia também leite, suco, ou seja, qualquer líquido. Nesse caso, 
da perspectiva semasiológica sua palavra $a b a$ era polissêmica (COUTO, 2002). A aprendizagem de L2, no entanto, é de natureza um tanto diferente. Para começo, é preciso distinguir aprendizagem monitorada, na escola, de aprendizagem "na rua". A primeira segue, em grande parte, o caminho semasiológico. Parte de palavras, frequentemente escritas em um livro, e procura lhes atribuir um sentido. A segunda pode lançar mão dos dois princípios. Quem se vê em um país aloglota tem que se fazer entender, seja lá como for. Assim, em alguns casos precisa saber como se diz algo ou qual é o nome de determinada coisa (onomasiologia), em outros, o que significam as palavras que foram ouvidas ou lidas (semasiologia).

Ainda de acordo com Baldinger (1966, p. 34), "a onomasiologia, tal como a concebemos, não é mais a ciência estreita, ligada às "Wörter und Sachen". Pelo contrário, ela "estuda a realização linguística dos conceitos em qualquer domínio do léxico (e mesmo em todos os domínios da língua)". Como se vê, para esse autor inclusive fenômenos morfológicos e sintáticos podem ser estudados da perspectiva onomasiológica ou da semasiológica.

Por fim, é importante lembrar que existem muitas publicaçóes acadêmicas na linha onomasiológica e na semasiológica. Para dar apenas dois exemplos da primeira, no final da década de 90 saíram dois artigos em alemão sobre partes do corpo em português. O primeiro é Kröll (1997), sobre os nomes de vagina. O autor encontrou mais de 90 nomes para ela. O segundo é Kröll (1998), a respeito dos nomes dos testículos, num total de mais de 90 denominaçôes. Nos dois casos, infelizmente, o autor simplesmente apresenta uma lista de nomes, sem nenhuma tentativa de interpretação.

\section{A relação língua-mundo}

Da acordo com Fill (1987), uma das áreas de maior interesse na língua são suas relaçôes com o mundo. Pois bem, na história da filosofia da linguagem tem havido duas posiçóes básicas a respeito dessas relações. Partindo do signo triádico de Peirce, temos uma primeira posição que afirma que a linguagem $(\mathrm{L})$ se interpõe entre nós e o mundo (M). Simbolizando o "nós" por população (P), essa visão pode ser representada como $\mathrm{P}-\mathrm{L}-\mathrm{M}$. De acordo com ela, não temos acesso direto ao mundo, mas apenas mediante a linguagem. Os defensores dessa tese afirmam que a linguagem cria o mundo, como faz a tradição que vem de Herder, passa por Humboldt até a teoria dos campos semânticos de Trier, 
Weisgerber e outros, na Europa, e a hipótese Sapir-Whorf, nos Estados Unidos. Uma das versões mais radicais dessa hipótese está representada pelo construtivismo radical (GLASERSFELD, 1989).

A outra visão afirma justamente o contrário, que somos nós, o povo ou população, que nos interpomos entre a linguagem e o mundo, de acordo com a representação $\mathrm{L}-\mathrm{P}-\mathrm{M}$. Para ela, nós temos acesso direto ao mundo, sem o intermediário da linguagem. É a população que cria a linguagem, partindo de sua práxis diária no meio ambiente em que vive. O que levou alguns autores a defenderem o construtivismo radical é o fato de que, após formada, a linguagem adquire uma relativa autonomia frente ao mundo, permitindo-nos falar do que existe, do que ainda não existe e até do que provavelmente nunca existirá, como na palavra "unicórnio", na ficção, na poesia etc. Para mais discussão sobre o assunto, pode-se consultar diversas passagens de Couto (2007), sobretudo as páginas 122-136.

No contexto de onomasiologia versus semasiologia, as duas visões têm sido postas em prática. Assim, no início dos estudos, os partidários da escola Wörter und Sachen, pendiam para a visão de que a linguagem surge como projeção de coisas, ações, qualidades e relaçóes existentes no mundo. Porém, os partidários dos campos semânticos têm pendido para o lado oposto, o de que é a linguagem que cria o mundo, como fica muito claro no humboldtiano confesso Leo Weisgerber.

A despeito de tudo isso, as reflexões sobre a linguagem surgiram justamente da perspectiva de algo como a das Wörter und Sachen, ou seja, da relação entre palavra e coisa. Isso pode ser visto tanto entre os gregos quanto entre os orientais. Em ambos os casos, o que predominava era a Theorie der Benennung, ou seja, a teoria da denominação (AMMIROVA; OL'CHOVIKOV; ROŽDESTVENSKIJ, 1980, p. 37-57). Entre os chineses, os sábios taoístas e confucianistas defendiam aproximadamente a mesma coisa (HANSEN, 1983). Um linguista de nosso tempo que defende essa tese é Haiman (HAIMAN, 1980).

Na verdade, a combinação da visão onomasiológica com a semasiológica mostra que as duas correntes de pensamento estão corretas. Nenhuma delas tomada isoladamente detém toda a verdade. Por um lado, a linguagem surgiu filogeneticamente, e surge ontogeneticamente, seguindo o percurso onomasiológico. Após formada, ela se amplia, adquirindo uma relativa autonomia frente ao mundo. Entre outros meios pelos quais isso ocorre, temos a polissemia, a homonímia, os processos metafóricos e os metonímicos. Isso merece um tratamento à parte, mas aqui não há espaço para discutir tudo. O que vou fazer 
é mostrar que também na gramática podemos ver essa ampliação do poder referencial da linguagem.

Comecemos pela sintaxe. A famosa frase de Chomsky, Colorless green ideas sleep furiously, serve de ponto de partida para a discussão. Com efeito, ele pôde criá-la, e nós o seu equivalente Ideias verdes incolores dormem furiosamente, porque a língua já dispunha de regras para produzir frases perfeitamente aceitáveis gramaticalmente, como tall slim girls walk elegantly ou, em português, Fonemas oclusivos surdos ocorrem frequentemente. Vale dizer, depois de surgir para produzir frases utilizáveis em situações normais como a de uma aula de fonologia, a língua permite formar até mesmo frases que só são produzidas por linguistas e/ou por brincadeira.

$\mathrm{Na}$ morfologia também podemos ver essa relativa independência que a língua tem com respeito ao mundo. Após adquirir regras para formar palavras como con.stitu.cion.al.ismo, ela permite aos falantes produzirem também re.stitu.cion.al.ismo, pelas mesmas regras, mesmo que essa forma (ainda) não tenha sido ativada. Até na fonologia isso acontece. Por exemplo, as regras de formação de sílabas que entram nos lexemas dão instrumento aos falantes para produzirem sílabas não só do tipo /fres/ (fres.co) e /frès/ (fres.ta) mas também uma sílaba como /flès/. Até onde pude investigar, /flès/ ainda não foi usada em nenhuma palavra da língua, mas está latente na gramática fonológica do português, inativada. Tanto que se alguém inventar um novo tablete de chocolate e lhe der o nome "taflés" ninguém estranhará. Em suma, a língua surgiu da observação do mundo. Porém, após formada, ela adquire uma relativa autonomia, permitindo criar novos mundos (ficção) e até falar de coisas absurdas, como quadrado redondo ou a frase de Chomsky recém-mencionada.

\section{Onomasiologia e semasiologia na Ecolinguística}

Ecolinguística tem sido definida como sendo o estudo das relações entre língua e meio ambiente. Aqui, meio ambiente é entendido como o é na Ecologia, em que é parte de um ecossistema. Faz-se necessário, portanto, averiguar quais são os componentes do ecossistema e quais são seus equivalentes linguísticos. Seus componentes são uma população de organismos com o respectivo meio ou habitat (biótopo), as inter-relações que se dão entre os organismos e esse meio, bem como entre os membros da população entre si. O equivalente linguístico do primeiro tipo de inter-relações (interações) é a referência, o das do primeiro tipo é a comunicação. Ao ecossistema ecológico, corresponde o ecossistema 
linguístico, no caso, ecossistema natural da língua, também conhecido como ecossistema fundamental da língua, que consta de um povo, vivendo eu seu próprio território e falando sua própria língua. No caso, o meio ambiente da língua são o território e os membros da população, como corpos físicos. Juntos eles (população e entorno) constituem o mundo ao qual sua linguagem se refere. Para a onomasiologia, e para a semasiologia, é esse mundo ou meio ambiente da língua que interessa, pois é nele que está grande parte das coisas a que as palavras se referem. Deve-se observar que dessa perspectiva a língua não é reificada, uma vez que ela se equipara às inter-relaçôes dos organismos no seu habitat ou território. Mais especificamente, ela é basicamente interação comunicativa. Quando falamos em meio ambiente da língua, não estamos referindo a um "lugar" em que a "coisa" língua se localizaria, mas ao locus das inter-relações que ela é.

Acontece que, como acabamos de ver, após formada (tanto ontogenética quanto filogeneticamente), a língua adquire uma relativa autonomia frente ao mundo, podendo inclusive criar outros mundos, ou meios ambientes. Um deles nem é tão abstrato assim. Trata-se do mundo mental, que nos leva a falar de um ecossistema mental da língua. Constatamos que aí o meio ambiente da língua, ou seja, o mundo em que as relações se dão é constituído pelo cérebro. Melhor dizendo, ele é constituído pelas conexôes neurais, nas quais se dá o surgimento, o uso, a transformação e, eventualmente, a morte da língua. Por fim, temos o ecossistema social da língua. Evidentemente, ele é constituído pela sociedade e a língua, em conjunto. No caso, a sociedade é o meio ambiente social da língua.

Diante do que acaba de ser dito, é preciso deixar claro o que se entende por mundo quando dizemos que as palavras da língua se referem a coisas do mundo. Do ponto de vista da língua, como acabamos de ver, existem três "mundos" (meios ambientes), que são o natural, o mental e o social. Os estudiosos de onomasiologia e de semasiologia, sobretudo os ligados à escola Wörter und Sachen, no mais das vezes têm investigado a relação entre palavras e coisas do mundo natural. De fato, temos muitas palavras que se referem a coisas propriamente ditas desse mundo, tais como árvore, rio, pedra, nuvem, estrela, cavalo etc. Temos também aquelas que se referem a situaçôes, não propriamente a coisas. Alguns exemplos que podem ser dados são dia, noite, frio, calor, vento etc.

Além das coisas e situações, no mundo natural, podemos identificar, e identificamos, açōes, qualidades e relações. Entre as açōes podemos citar as de $i r$, vir/voltar, comer, trabalhar, dar (algo a alguém), relampear, chover, ventar etc. 
Do âmbito das qualidades, poderíamos dar como exemplo branco, preto, vermelho, grosso / fino, grande / pequeno, alto / baixo, entre inúmeras outras. Por fim, entre as relaçôes que se dão entre as coisas do mundo poderíamos mencionar dentro / fora, em cima / embaixo, antes / depois, à direita / à esquerda, as que indicam movimento na direção de um alvo $(\rightarrow \mid)$ ou a partir dele $(\mid \rightarrow)$, além das de verticalidade e horizontalidade. Essas relações serão examinadas em mais pormenores na seção 7. Por fim, temos as palavras que se referem ao mundo mental e ao social, assunto que, infelizmente, não é possível desenvolver aqui.

Diante do que acaba de ser visto, a língua não é uma realidade só social, como querem alguns ramos da Sociolinguística e da Análise do Discurso, entre outros, nem, muito menos, uma realidade só mental, como quer a gramática gerativa e toda a filosofia racionalista. Sequer é ela algo que exista apenas para a descrição do mundo natural, como davam a entender as primeiras reflexóes filosóficas sobre a linguagem, tanto gregas quanto indianas e chinesas, além de filósofos como o "primeiro" Wittgenstein. Na verdade, a língua é tudo isso. Se perguntarmos se ela é uma realidade social, a resposta será sim. Se perguntarmos se é uma realidade mental, teremos uma resposta afirmativa. Se, por fim, indagarmos se ela é uma realidade natural, ou melhor, biológica, a resposta será, outrossim, positiva. Na verdade, a língua é uma realidade biopsicossocial. Portanto, o que os onomasiologistas têm feito restringe-se quase que exclusivamente à relação entre língua e mundo natural, e de modo unidirecional. No entanto, é preciso incluir aí também "as coisas" do mundo mental e as do social, ou seja, do mundo psicossocial, nos dois sentidos entre "palavra" e "coisa". Só esse assunto mereceria todo um tratado. Como não há espaço suficiente para abordá-lo em profundidade, pode-se ler Couto $(2007,2009 b)$.

\section{Onomasiologia e semasiologia na ecologia da interação comunicativa}

Os conceitos de onomasiologia e semasiologia têm aplicação também na interlocução, no diálogo. Como sabemos, o diálogo ocorre no contexto da ecologia da interação comunicativa, que vem sendo estudada parcelarmente por algumas vertentes da Linguística. Nós falamos para ser ouvidos, para enviar a nosso interlocutor uma solicitação, que pode ser uma ordem, um pedido, uma pergunta ou uma informação. O ouvinte, por seu turno, se transforma em falante e atende (ou não) a essa solicitação. Seu enunciado geralmente é uma informação, 
que equivale a uma oração declarativa, afirmativa ou negativa, conforme o caso. Existem outros tipos de enunciados que não interessam diretamente aqui, tais como o vocativo, a exclamação etc. A onomasiologia e a semasiologia têm mais a ver com o que se chamou de célula da comunicação, que é o todo formado pela pergunta e a resposta. A fala meramente fática serve apenas de contraponto a elas.

Como Kurt Baldinger já havia observado, "A onomasiologia visualiza os problemas sob o ângulo do que fala, daquele que deve escolher entre diferentes meios de expressão. A semasiologia focaliza os problemas sob o ângulo do que ouve, do interlocutor que deve determinar a significação da palavra que ele entende dentre todas as significações possíveis" (BALDINGER, 1966, p. 30). Nesse excerto, está dito o essencial do que interessa no presente momento. Mas os clássicos desses estudos também se manifestaram sobre o assunto, mesmo que indiretamente.

Em seu ensaio "Sachen und Wörter", de 1912, Schuchardt afirmou que "não é meramente a palavra proferida que tem um conteúdo [...], mas aquela que é pronunciada inúmeras vezes, sendo que ela é a palavra do falante". Aqui fica patente que a palavra não existe por si só, como se pairasse no ar. Quando se fala em diálogo, em linguagem em uso, trata-se sempre da palavra de alguém, daquele que fala no momento em que fala. Linguagem é interação comunicativa, é o falar, como não se cansava de insistir Eugenio Coseriu.

Rudolf Meringer não fica atrás de Schuchardt, e não só pela disputa que mantinha com ele. Para o primeiro, "tudo que facilita a interação, facilita a vida em comunidade, e a língua comum é o maior facilitador da interação". Ele chega a afirmar que a mudança linguística se dá na imitação imperfeita. Em suas palavras, "a imitação exerce um papel decisivo nas mudanças linguísticas". Em outra passagem, ele assevera que "a imitação se dá na interação e é por ela determinada” (MERINGER, 1912). Veja-se, por exemplo, o caso de um grupo de migrantes em um país aloglota. Em seu desejo de se adaptar ao modo de se comunicar no novo meio, sua língua entra em um processo de atrição, que pode levar a uma mudança de língua. Para falar de coisas aparentemente as mesmas, passam a usar palavras diferentes, uma vez que de uma língua diferente.

Tudo isso ocorre porque, ainda nas palavras de Meringer, e reforçando o que Schuchardt já havia dito, "a gente imita não apenas o modo de falar, mas todo um tipo de pessoa, um modo de sentir e de agir", vale dizer, sua maneira de encarar o mundo. Nós sempre queremos nos adaptar ao meio em que nos encontramos, pois, do contrário, não seremos aceitos. Nessa adaptação, acabamos alterando nossos hábitos, inclusive os linguísticos. 
A estas alturas, Meringer já apontava para o que bem mais tarde foi dito no contexto da ecologia da evolução linguística por Mufwene (2001). De acordo com este último, a língua muda porque cada geração replica a linguagem da anterior de maneira imperfeita. Melhor dizendo, usa semasiologicamente as mesmas palavras na aparência, porém aplicadas a coisas ligeira ou totalmente diferentes. Por outro lado, pode também usar aparentemente palavras diferentes para conteúdos aparentemente os mesmos, da perspectiva onomasiológica. Nas gírias, por exemplo, numa determinada época se diz é isso aí bicho!, em outras é isso aí cara! e numa terceira época, é isso aí véi!. Mudam-se as palavras, ficam os conceitos, embora usados em contextos diferentes. A evolução linguística é cíclica (COUTO, 2012).

Acima já foi feita referência à aquisição de linguagem pela criança e a aprendizagem de L2 pelo adulto. Vimos que a primeira parte claramente de uma perspectiva onomasiológica. Primeiro a criança começa a identificar os objetos existentes em seu meio, aí inclusas as açōes referentes a eles. Só após essa etapa ela atribui um nome a essas coisas. $\mathrm{O}$ processo é muito parecido em todas as crianças de todo o mundo, como se pode ver em Clark (1993). No caso da aprendizagem de L2 monitorada, na escola, frequentemente se parte da palavra e se procura por seu conteúdo, num percurso visivelmente semasiológico. Tudo isso se dá no contexto da ecologia da interação comunicativa.

\section{7. $O$ estudo onomasiológico e semasiológico das preposições}

Em geral pensamos que as preposições não têm nada a ver com o mundo extralinguístico. Na gramática gerativa, por exemplo, elas são incluídas nas categorias funcionais, não nas lexicais, que, estas sim, teriam referência fora da língua. Alhures, elas são chamadas de palavras vazias, por oposição às que designam algo fora da língua, que são as palavras cheias. É bom ter em mente, porém, que a língua existe para a comunicação, para nos interagirmos uns com os outros sobre o mundo. Em princípio, tudo nela visa a esse fim. Nada é desprovido de significado, nada aparece na frase apenas como enfeite, de modo inteiramente desconectado do mundo e do como se fala dele, lembrando-se que "mundo" compreende o natural, o mental e o social, como já vimos (os dois últimos, às vezes são chamados de psicossocial). As preposições não constituem exceção a esse princípio. 
Como decorrência do sentimento de que as preposições não teriam nada a ver com o mundo, os dialetólogos e os geógrafos-linguistas não lhes deram muita atenção, talvez nenhuma. É bem verdade que as preposiçôes não se referem a "coisas" do mundo. Tampouco se referem a ações ou a qualidades. Porém, elas designam relaçôes entre as coisas. $\mathrm{Na}$ Grammaire générale et raisonnée, está dito que as preposiçōes foram "inventadas para o mesmo uso, que é de indicar as relações que as coisas têm umas com as outras" (ARNAULD; LANCELOT, 1830, p. 62). Na filosofia, temos a tese de ninguém menos que Ludwig Wittgenstein. De acordo com esse autor, "os elementos da figuração (Bild) estando uns em relação aos outros de um modo determinado, isto representa as coisas estando umas em relação às outras" (2.15). Pouco depois ele acrescenta que "a forma de afiguração (Abbildung) é a possibilidade de que as coisas estejam umas em relação às outras como os elementos da figuração" (2.151) (WITTGENSTEIN, 1968, p. 59).

Por incrível que possa parecer, as preposiçōes constituem uma das áreas do vocabulário das línguas mais interessantes para o estudo semântico do léxico. Nelas, mais do que em muitas outras áreas semânticas, ou melhor, campos semânticos, fica claro que o estudo deve começar pelo referente, pela coisa, no sentido da escola das Wörter und Sachen, ou das Sachen und Wörter. A pesquisa na área das preposiçôes tem demonstrado que uma das metodologias mais interessantes é a que começa pelo ponto de vista onomasiológico.

Quando eu comecei a estudar as preposiçôes, com as conjunções, no início da década de 1970, fi-lo começando das "coisas", ou melhor, das relaçôes entre as coisas. Assim, Couto (1972) é o resultado de uma dissertação de mestrado, defendida na USP, que tinha por base as preposiçōes espaciais. $\mathrm{Na}$ época, eu estava muito influenciado pela pesquisa de Bernard Pottier sobre o assunto (POTTIER, 1968, 1969; POTTIER; AUDUBERT; PAIS, 1973). Além disso, tomei conhecimento da detalhada investigação que se vê em Borba (1971) sobre as preposiçōes portuguesas. Após um longo interregno, o estudo teve continuidade, pelo menos em parte, em Couto (1994, p. 118-125). Posteriormente, o procedimento foi aplicado no estudo das preposições do crioulo português da Guiné-Bissau (COUTO, 2007a; 2007b; 2009a). A essas alturas, tomei conhecimento de uma investigação de John Wilkins, que já havia proposto algo semelhante no século 17 . O resultado de tudo isso desembocou na ecologia das relaçóes espaciais, mostrada na figura seguinte. 


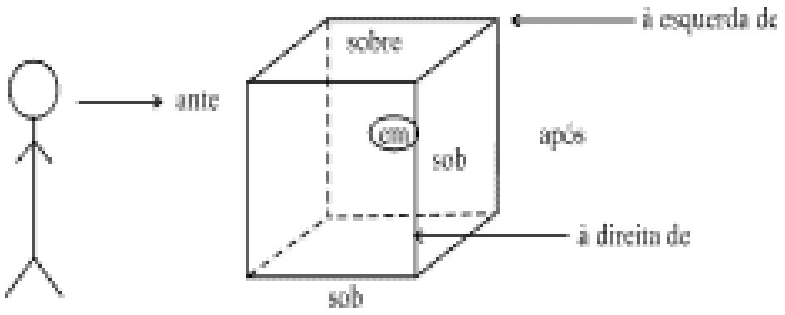

A figura representa, de modo estilizado, os principais tipos de relação que podem se dar entre as coisas do mundo. Em primeiro lugar, é de se salientar a relação de interioridade, por oposição à de exterioridade. A primeira é representada pela preposição $\mathrm{em}$, ao lado da locução prepositiva dentro de. A segunda é codificada por uma locução prepositiva de valor geral, que é fora de. Isso significa que, em princípio, todas as demais relações mostradas na figura são de exterioridade, o que implica que interioridade se opóe a todas as demais posições. Por indicar a posição mais universal, a interioridade, em é considerada a preposição por excelência, e é uma das poucas que existe em todas as línguas do mundo. Isso se reforça pelo fato de a interioridade não depender de um observador. $\mathrm{O}$ caroço está dentro da fruta independentemente de alguém para observar o fato. A interioridade independe de outra dimensão muito importante para a vida na face da terra, que é de horizontalidade versus verticalidade.

Considerando a superfície da terra, há mais uma posição da figura que, embora dependente dessas dimensões, independe de observador. Trata-se da superioridade (representada por sobre), por oposição a inferioridade (codificada por sob). Uma pedra pequena em cima de uma maior está lá quer haja alguém para observar a relação, quer não. $\mathrm{O}$ mesmo acontece se a menor estiver embaixo da maior. Todas as demais posiçóes da figura existem apenas da perspectiva de um observador. A mais conspícua delas é a de anterioridade (ante, antes de) versus posterioridade (após, depois de). Em seguida vem a de lateralidade, que compreende a dexteridade (à direita de) e a sinistridade (à esquerda de), dimensões já observadas pelo estudioso dos campos semânticos André Jolles. É interessante notar que essas duas posições geralmente só são codificadas por locuções prepositivas, não por preposições simples, o que sugere que as demais relações seriam mais importantes do que elas em nossas interações com o mundo.

Há pelo menos mais uma localização da figura. É o caso de ante, que, se for olhado por um segundo observador, será um ponto na linha que vai do 
primeiro observador até o cubo, um ponto que intermedeia ambos (posição de interidade), codificado pela preposição entre. Essa posição tem muitas afinidades com a de interioridade, tanto que a preposição que a codifica tem a mesma raiz. Aliás, o equivalente inglês de entre (between) pode ocorrer acompanhado do equivalente de em (in), ou seja, in between (no meio de).

Até mesmo as chamadas preposições de movimento podem ser incluídas na figura, embora Pottier tenha proposto um esquema diferente para representálas. Nesse caso, teríamos as que indicam movimento em direção a um ponto $(\rightarrow \mid)$ e as que partem dele $(\mid \rightarrow)$. Na nossa figura, podemos considerar que preposiçóes como $a$, para e até vão na direção do cubo (preposições de destino), ao passo que de e desde indicariam movimento a partir dele (preposições de origem), tudo da perspectiva do observador. Por fim, temos as preposiçōes de percurso, como por e ao longo de. A primeira indica duas coisas: primeiro, as redondezas do cubo e do observador (ele está por aî); segundo, algo como sinônimo de ao longo de (Vim pelo caminho que vai de $A$ a $B$ ). A segunda poderia referir-se ao percurso que vai do observador até o cubo, ou até mesmo algo que percorre a sua superfície. $\mathrm{O}$ inglês distingue o movimento que passa pela superfície do cubo (across) do que passa por seu interior (through).

Tudo que foi dito até aqui parte do ponto de vista onomasiológico. Porém, é preciso complementar esse estudo com a ótica semasiológica. É preciso partir de cada lexema preposicional (ou de cada locução prepositiva) e indagar quais são seus usos. Trata-se de uma tarefa extremamente difícil. Manuel Rodrigues Lapa, por exemplo, apresenta diversos usos de algumas preposiçóes. Ele começa com sobre, que, além do sentido prototípico, como em o livro está sobre a mesa, é usado em sentidos derivados, a exemplo de a janela deitava sobre o jardim. Menciona ainda acepçóes nocionais, em sobre ser parvo, éainda mauzinho. Faltou o uso no sentido de assunto, como falar sobre história. Só para a preposição "de", o autor menciona acima de dez usos diferentes, aí não incluso o de posse (livro de Pedro) (LAPA, 1970, p. 194-205). Em Borba (1971) também há um longo estudo semasiológico das preposições, ou seja, sobre os diversos usos de cada preposição portuguesa.

Note-se que semasiologicamente, há uma verdadeira dança das preposições. Assim, a pode tomar o lugar de em (moro à rua Tiradentes) e em o de a (vou em São Paulo). Às vezes, os falantes não sabem se devem usar em ou de (literatura $\underline{\text { dol }}$ no Brasil). No aprendizado de línguas estrangeiras, são as preposições que apresentam as maiores dificuldades. Ainda no caso do inglês, nunca sabemos se nosso em deve ser traduzido por in, at ou on. Causam-nos 
estranheza construções como eating on the bus is prohibited (é proibido comer no ônibus), the town is on the island (a cidade está na ilha) e, sobretudo, the bear is in the hills (o urso está nas montanhas).

Só a dialética entre onomasiologia e semasiologia pode dar conta desses diversos usos. Quando os examinamos a fundo, notamos que nenhum deles perdeu o pé da base onomasiológica original e originária, pois só ela nos permite encontrar o fio condutor. Nem mesmo os usos temporais e nocionais (relações aparentemente abstratas), na terminologia de Pottier, fogem por completo desse princípio. A significação fundamental das preposições, sua significação prototípica, está dada na ecologia das relaçôes espaciais da figura supra, que nos fornece a visão onomasiológica.

Para que o estudo semântico das preposições seja completo, é necessário partir do ponto de vista das relaçôes entre as coisas do mundo (natural, mental, social), ou seja, da perspectiva onomasiológica. Porém, esse estudo tem que ser complementado com a perspectiva oposta, que é o estudo dos diversos usos que as línguas fazem de cada preposição individual. É a virada semasiológica. Grande parte dos estudos modernos sobre preposições segue apenas esse ponto de vista, como se as preposições fossem relações abstratas pairando no ar, e que a tarefa do investigador seria apenas ver sua função sintática. $\mathrm{O}$ procedimento mais seguro é partir das relações concretas do mundo, ir na direção das palavras que as codificam e, em seguida, partir dessas palavras e averiguar que usos a língua faz de cada uma delas ulteriormente. Enfim, há uma relação dialética entre onomasiologia e semasiologia, cujo ponto de partida é sempre a onomasiologia.

\section{Onomasiologia e semasiologia na morfossintaxe}

Quando se fala em onomasiologia e semasiologia, o que vem à mente de imediato é o estudo de itens lexicais. Não é comum falar-se em estudos sintáticos (e morfológicos) dessa perspectiva. A despeito disso, gostaria de mostrar que é possível identificar alguns casos de investigação sintática que se enquadrariam nessa visão de linguagem. Meu objetivo é simplesmente mostrar que existem outras maneiras de se estudar morfossintaxe que não a gerativa, de sólida tradição.

Vejamos a sintaxe. No final da década de 1950, Hennig Brinkmann (Die deutsche Sprache, Düsseldorf: Schwann, 1962) investigou a sintaxe alemã, levando em conta o conteúdo. Frases como João dorme ele classificou como "frases de acontecimento" (Vorgangssatz); João lê o livro seria uma "frase de ação" 
(Handlungssatz); João é diligente, "frase de julgamento" (Urteilssatz) ou "adjetival" (Adjektivsatz); João é professor, "frase identificadora" (Identifizierungssatz) ou "substantival" (Substantivsatz). Como disse Helbig (1975, p. 161), "os modelos frasais de Brinkmann não são idênticos a estados de coisas, mas a determinadas maneiras de vê-las". Helbig fala também da "orientação conteudística do modelo de Brinkmann". Mas, quem se aproxima mais da visão onomasiológica é o linguista russo Vladimir G. Admoni (contemporâneo de Brinkmann), que critica energicamente a gramática de conteúdo (Inhaltbezogene Grammatik) de Weisgerber. Para Admoni, as frases mais complexas resultam da observação do mundo. Ele chega a admitir um paralelismo entre estrutura da língua e organização do mundo. Na chamada gramática funcional que foi praticada na ex-Alemanha Oriental, podemos ver a abordagem onomasiológica mais claramente. Ela interpreta os exemplos de Brinkmann, relacionando-os às coisas (sachbezogen), como é o caso de W. Ludwig, F. Hahn e H. Hamann.

No início da década de 1980, eu fiz um estudo semelhante, no contexto da gramática estratificacional (LAMB, 1966; LOCKWOOD, 1972; COUTO, 1982), atualmente chamada de linguística neurocognitiva. Como herdeiro da glossemática de Hjelmslev, esse modelo de análise linguística leva em conta o lado expressão e o lado conteúdo da linguagem. Se a análise vai da expressão para o conteúdo, temos a visão semasiológica; no sentido contrário, a onomasiológica, embora o criador da teoria não tenha usado esses termos. É a onomasiologia que tentei aplicar ao português, também sem usar o termo (COUTO, 1981).

Partindo de um evento como "um caçador definido que matou um leão definido no passado", cheguei a resultados interessantes, seguindo o que Lockwood (1972) fizera para o inglês. A primeira e mais óbvia codificação desse evento é O caçador matou o leão, em que "O caçador" é o tema ou tópico, a informação velha, enquanto que "matou o leão" é o rema ou comentário, a informação nova, nos termos da perspectiva funcional da sentença da Escola de Praga. Mas, podemos dizer também O leão foi morto pelo caçador, apenas colocando ênfase no paciente da ação. Se a ênfase for muito forte, poderíamos dizer É o caçador que matou o leão ou, então, É pelo caçador que o leão foi morto, respectivamente. Se houver uma superênfase no paciente, poderíamos ter $E$ o leão que o caçador matou e É o leão que foi morto pelo caçador. Se, finalmente, a ênfase for dada à própria ação, teríamos algo como $O$ que o caçador fez foi matar o leão.

Podemos ter até construçōes como $O$ fato de o caçador ter matado o leão (foi comentado por todo mundo), O fato de o leão ter sido morto pelo caçador (não 
alterou em nada as coisas), Morto o leão pelo caçador (as gazelas andaram livres pela savana) e $A$ morte do leão pelo caçador (não foi bem-vinda pelos ambientalistas), entre diversas outras possibilidades.

Pelo menos em tese, a virada semasiológica consistiria em partir de cada frase e averiguar a que situações ela se refere. Outra possibilidade talvez estivesse em pôr determinado termo em foco mediante maior intensidade da voz e/ou entoação. Com isso o valor de verdade (relação onomasiológica) da frase se manteria, mas, do ponto de vista do contexto, cada variante expressaria algo diferente. Algumas das frases já vistas poderiam ser expressas também como $O C A C ̧ A D O R$ (não o relâmpago) matou o leão, $O$ caçador matou $O L E \tilde{A} O$ (não o tigre) e $O$ caçador $M A T O U$ (não espantou) o leão. $\mathrm{O}$ mesmo vale quando a frase é analisada em termos de tema e rema, ou de tópico e comentário: o valor de verdade é o mesmo, mas o fato de determinado elemento ser posto em primeiro lugar (tópico) faz da frase um enunciado que comunica algo diferente de quando outro elemento é o tópico. Talvez a visão semasiológica fique mais patente quando procuramos pelo(s) estado(s) de coisas a que algumas frases ambíguas se referem. É o caso de Demos às meninas lindas flores. Se o acento frasal recair sobre "lindas", teríamos Demos às meninas lindas/flores, caso em que são as meninas que são lindas. Porém, se ele recair sobre "meninas", como em Demos às meninas/ lindas flores, as flores é que são lindas. Enfim, quando analisamos um enunciado no contexto da ecologia da interação comunicativa, que implica a visão onomasiológico-semasiológica, o mais importante não é apenas a estrutura sintática formal.

A chamada perspectiva funcional da sentença (PFS) da segunda fase da Escola de Praga, proposta por Vilém Mathesius e desenvolvida por Jan Firbas, já ia nessa direção. Em primeiro lugar, temos a informação dada, velha, presumivelmente conhecida do ouvinte, que é o tema. A informação nova é o rema. Além da ordem das palavras, do contexto e da entoação, a semântica tem um papel fundamental na análise dos enunciados. O enunciado é analisado não sintático-formalmente, mas de acordo com o modo como a informação está presente nele, como a distinção entre informação já conhecida (tema) e informação nova (rema) (HELBIG, 1975, p. 59-60).

Já no século 19 havia outras correntes que iam na direção de uma visão onomasiológico-semasiológica, como é o caso das gramáticas filosóficas (cf. ARNAULD; LANCELOT, 1830), pelo menos no que tange à relação linguagemmundo, melhor dizendo, à relação linguagem e pensamento. Em alguns autores estruturalistas, também se pode ver algo parecido, como é o caso do europeu Eugenio 
Coseriu e do americano William Bull (1968). Este último estudou o sistema verbal do espanhol partindo das situaçōes a que as diversas flexōes se referiam.

Um sintaticista de linha formal poderia achar que análises como essas não são sintáticas. No entanto, deve ser observado que estamos lidando com arranjos diferentes (alternativos) de palavras para descrever aproximadamente o mesmo evento, para falar dele. Ora, ninguém discordaria da asserção de que estudar arranjos de palavras seria lidar com fenômenos sintáticos. Além do mais, a língua existe para falarmos do mundo (social, mental, natural). No início filogenético e ontogenético, ela surge justamente para isso, as palavras são projeçôes diretas de aspectos desses "mundos", e os conetivos são projeçōes diretas das relaçōes entre coisas (Sachen). Com o desenvolvimento sociocultural, a língua vai adquirindo uma relativa autonomia frente a essas coisas e relaçōes, permitindo falar até do absurdo. Aí temos a virada semasiológica na língua como um todo, momento em que se parte das palavras para criar "coisas". É essa virada que faz alguns filósofos da linguagem pensarem que é a língua que cria o mundo. Assim procedendo, esquecem que há um momento prévio, onomasiológico, sem o qual a linguagem seria uma verborreia vazia, se é que se pode falar em linguagem nessas circunstâncias. Sem ele seria impossível a comunicação. Enfim, é porque houve o "momento" onomasiológico anteriormente que pôde haver a virada semasiológica, que permite inclusive formar frases como a de Chomsky mencionada acima.

No caso da morfologia, o que realmente interessa é a composicional e a derivacional, uma vez que a flexional está estritamente ligada à sintaxe, ou seja, a flexão existe em função da concordância sintática. Ela não contribui muito para a interação comunicativa. Tanto que, na zona rural do Brasil, As menina pequena chego tudo atrasado contém aproximadamente a mesma informação que Todas as meninas pequenas chegaram atrasadas do português estatal (padrão), a despeito de na segunda todas as palavras estarem no plural, e todas menos o verbo no feminino. A explicação ecolinguística é que em situações em que não há pressão da norma estatal tudo que for dispensável em geral é dispensado, como é o caso dessas flexões em gênero e número.

Ao falar da relação língua-mundo na seção 4, já tangenciei a questão da derivação. $\mathrm{O}$ simples fato de ela ter sido mencionada naquela seção já sugere que de algum modo ela tem a ver com a referência. Com efeito, derivamos novas palavras justamente para designar algo novo a que precisamos nos referir em nossas interaçōes quotidianas. Tanto a derivação quanto a composição existem para aumentar o poder referencial da língua mediante o uso de recursos internos, que são reciclados, ou melhor, reutilizados. Assim, vimos que a formação 
morfológica restitucionalismo mesmo não estando ativada, poderia sê-lo a qualquer momento que se fizesse necessário. Ela faz parte da competência morfológica dos falantes, com a única diferença de que está inativada.

$\mathrm{O}$ mesmo se poderia de dizer da formação composicional limpa-rosto, por exemplo. Não a encontrei no Aurélio nem no Houaiss. Tampouco a ouvi da boca de falantes de português brasileiro. No entanto, ela está lá, inativada, como potencialidade da língua ainda não utilizada. A gramática morfológica a prevê. Ela é paralela a formaçóes ativadas como limpa-vidro, limpa-pés, limpa-pasto etc., presentes nos dois dicionários. Se alguém algum dia inventar um produto para limpar o rosto e lhe der o nome em questão, nenhum falante de português acharia a formação estranha.

Por fim, gostaria de ressaltar que inclusive os textos podem ser analisados da perspectiva onomasiológico-semasiológica. Por exemplo, do ponto de vista onomasiológico, um estado de coisas ou uma paisagem podem ser objeto de muitas descrições diferentes. Um evento pode ser narrado de diversas maneiras, e assim por diante. Por outro lado, um texto descritivo ou um narrativo podem ser interpretados de maneiras diferentes por diferentes leitores, cada um ligando-o a um estado de coisas diferente, o que constituiria a visão semasiológica. $\mathrm{O}$ assunto merece uma investigação mais aprofundada do que a que o que foi dito acima.

\section{Observações finais}

Como os conceitos de onomasiologia e semasiologia surgiram no contexto dos estudos filológicos iniciados no século 19, não têm sido muito populares na linguística moderna. Isso é uma pena, pois, qualquer estudo semântico de qualquer área do léxico deveria levar os dois em conta, sobretudo da perspectiva da língua como interação. Dever-se-ia partir da onomasiologia e complementá-la com a semasiologia.

Se ignorarmos as duas perspectivas, podemos incorrer em dois equívocos epistemológicos. O primeiro consiste em aderir apenas ao lado semasiológico. Nesse caso, estaríamos adotando a visão bíblica, de acordo com a qual "no princípio existia o verbo" [...] "e o verbo se fez carne" (JOÃO 1,1-14). Vale dizer, a coisa é derivada do nome. Seria cair numa espécie de verbocriacionismo, como o defendido pelo construtivismo radical. O equívoco oposto é o que poderíamos chamar de reflexo especular, de acordo com o qual a palavra contém a coisa em si ou, na melhor das hipóteses, a linguagem seria um reflexo mecânico do mundo, como na visão metafísica (WITTGENSTEIN, 1968). 
A única maneira de evitar essa esparrela é praticar semântica dialeticamente, ora partindo da onomasiologia e complementando-a com a semasiologia, ora indo na direção inversa, sempre fazendo uma complementar a outra. Esse procedimento não se aplica apenas ao nível do vocabulário, como os especialistas já salientaram. Pelo contrário, ele pode, e deve ser aplicado em todos os níveis, inclusive o morfossintático. Até mesmo no nível do texto. Sabemos que o escritor segue a perspectiva onomasiológica, mas o leitor parte do ponto de vista semasiológico, ele tem que tentar fazer o caminho inverso ao do autor do texto. Ele precisa descobrir o que o redator quis dizer, isto é, de que conteúdos ele partiu. O sucesso na comunicação entre escritor e leitor será tão mais eficaz quanto mais o segundo conseguir se aproximar do ponto de que o primeiro partiu. Por fim, até mesmo na ecologia da interação comunicativa a dicotomia é importante. O ponto de vista do falante é onomasiológico, ao passo que o do ouvinte é semasiológico. Dessa adaptação mútua onomosiológico-semasiológica surge o diálogo, o núcleo de uma visão ecolinguística dos fenômenos da linguagem.

\section{Nota}

1. O endereço é: <www1.ku-eichstaett.de/SLF/EngluVglSW/OnOn.htm>.

\section{Referências}

AMMIROVA, T. A.; OL'CHOVIKOV, B. A.; ROZDESTVENSKIJ, J. V. Abriss der Geschichte der Linguistik. Leipzig: VEB Bibliographisches Institut, 1980.

ARNAULD, A.; LANCELOT C. Grammaire générale et raisonnée. Paris: Auguste Delalain, 1830 (Republicada em 1969 por Republications Paulet, organizada por Michel Foucault).

BALDINGER, K. Semasiologia e onomasiologia. Alfa n. 9, p. 7-36, 1966.

BORBA, Francisco da Silva. 1971. Sistema de preposiçôes em português. 1971. Tese (Livre-Docência) - Universidade de São Paulo, 1971.

BULL, W. Time, tense and the verb. Los Angeles: The University of California Press, 1968. COSERIU, E. Teoría del lenguaje y lingüistica general. 2. Ed. Madri: Editorial Gredos, 1967.

CLARK, E. The lexicon in acquisition. Cambridge: Cambridge University Press, 1993.

COUTO, H. H. do. Os conetivos. 1972. Dissertação (Mestrado) - FFLCH-USP, 1972. 
COUTO, H. H. do. Codificação linguística de eventos. In: COUTO, H. H. do et al. (Org.). Ensaios de linguistica aplicada ao português. Brasília: Thesaurus Editora, 1981. p. 79-101.

COUTO, H. H. do. Linguistica e semiótica relational. Brasilia: Thesaurus Editora, 1982.

COUTO, H. H. do. O crioulo português da Guiné-Bissau. Hamburgo: Helmut Buske Verlag, 1994

COUTO, H. H. do. Aquisição de L1 por Aninha: uma visão ecológico-interacional. Revista planalto n. 1, p. 6-54, 2002.

COUTO, H. H. do. Ecolinguistica - estudo das relações entre língua e meio ambiente. Brasília: Thesaurus, 2007.

COUTO, H. H. do. The ecology of spatial relations: The case of Kriol prepositions. In: SCHRADER-KNIFFKI, M.; MORGENTHALER GARCÍA, L. (Org.). La Romania en interacción: entre historia, contacto y política. Frankfurt/Madri: Iberoamericana/Vervuert, 2007a. p. 479-514.

COUTO, H. H. do. Ecologia das relações espaciais - as preposições do crioulo guineense. Papia 17, p. 80-111, 2007b.

COUTO, H. H. do. On the so-called complex prepositions in Kriol. Révue roumaine de linguistique v. LIV, n. 3-4, p. 279-294, 2009a.

COUTO, H. H. do. Língua e meio ambiente. Revista de estudos da linguagem v. 17, n. 1, p. 143-178, 2009b.

COUTO, H. H. do. O tao da linguagem. Campinas: Pontes, 2012.

FILL, Alwin. Wörter zu Pflugscharen: Versuch einer Ökologie der Sprache. Colônia: Böhlau, 1987.

GLASERSFELD, E. von. Cognition, construction of knowledge, and teaching. Synthese v. 80, n. 1, p. 121-140, 1989.

GUIRAUD, P. La sémantique. Paris: Presses Universitaires de France, col. "Que sais-je?", 1969.

HAIMAN, J. The iconicity of grammar: isomorphism and motivation. Language v. 56, n. 3, p. 515-540, 1980.

HANSEN, C. Language and logic in Ancient China. Ann Arbor: University of Michigan Press, 1983.

HELBIG, G. Geschichte der neueren Sprachwissenschaft. Hamburgo: Rowohlt, 1975.

KRÖLL, H. Zu den Bezeichnungen für vagina im Portugiesischen. Lusorama n. 34, p. 27-51, 1997. 
KRÖLL, H. Zu den Bezeichnungen für testículos im Portugiesischen. Lusoraman. 35, p. 48-56, 1998.

LAMB, S M. Outline of stratificational grammar. Washington, D. C.: Georgetown University Press, 1966.

LAPA, M. R. Estilistica da língua portuguesa. 6. ed. Rio de Janeiro: Livraria Acadêmica, 1970.

LOCKWOOD, D. G. Introduction to stratificational linguistics. New York: Harcourt Brace Jovanovich, 1972.

MERINGER, R. Zur Aufgabe und zum Namen unserer Zeitschrift. Wörter und Sachen, Band III, p. 22-56, 1912.

MIAZZI, M. L. F. Introdução à linguística românica. São Paulo: Cultrix, 1972.

MUFWENE, S. The ecology of language evolution. Cambridge: Cambridge University Press, 2001.

POTTIER, B. Lingüistica moderna y filología hispánica. Madri: Editorial Gredos, 1968.

POTTIER, B. Grammaire de l'espagnol. Paris: Presse Universitaire de France, 1969.

POTTIER, B.; AUDUBERT A.; PAIS, C. T. Estruturas linguísticas do português. 2. ed. São Paulo: DIFEL, 1973.

SAUSSURE, F. Curso de linguistica geral. 5. ed. São Paulo: Editora Cultrix, 1973.

SCHAFF, A. Linguagem e pensamento. Coimbra: Livraria Almedina, 1974.

SCHUCHARDT, H. Sachen und Wörter. Anthropos, tomo VII, p. 827-839, 1912.

SILVA NETO, S. Manual de filologia portuguesa. 2. ed. Rio de Janeiro: Livraria Acadêmica, 1957

TRIER, J. Über die Erforschung des menschlichen Wortschatzes. In: HAMP, Eric P., FRED W. H.; AUSTERLITZ, R. (Org.). Readings in linguistics III. Chicago: Chicago University Press, p. 90-95, 1966.

ULLMANN, S. Semântica. 2. ed. Lisboa: Fundação Calouste Gulbenkian, 1970.

WITTGENSTEIN, L. Tractatus logico-philosophicus. São Paulo: Cia. Ed. Nacional / EDUSP, 1968. 